\title{
Conservadorismo Social: Opiniões e Atitudes no Contexto da Eleição de 2002
}

\author{
Katia Mika Nishimura \\ Programa de Doutorado em Ciências Sociais \\ da \\ Universidade de Campinas
}

\begin{abstract}
Resumo
A autora estuda as tendências do comportamento social dos brasileiros com base em posicionamentos sobre temas como o homossexualismo, o aborto, o papel da mulher e a hierarquia social e suas relações com variáveis demográficas, socioeconômicas e de comportamento político. Apesar de verificar a existência de um comportamento social conservador, os dados sugerem que este não se traduz, necessariamente, nas escolhas políticas dos indivíduos. O artigo utiliza os dados do ESEB 2002.
\end{abstract}

Palavras-chave: Estudo Eleitoral Brasileiro; conservadorismo; comportamento eleitoral; comportamento social

\begin{abstract}
The author studies the tendencies of the Brazilian electorate social behavior based on their positioning about homossexualism, abortion, feminism and social hierarchy aspects and she analyses their relationship with socioeconomic, demographic and political variables. The author finds conservative trends in the social behavior, that do not seem to influence their electoral choices. The data come from the 2002 Brazilian Electoral Study.
\end{abstract}

Keywords: Brazilian Electoral Study; conservantism; electoral behavior; social behavior 


\section{Introdução}

Este artigo aponta algumas tendências do comportamento social da sociedade brasileira na eleição presidencial ocorrida em 2002. Trata-se das atitudes e posicionamentos referentes a temas e questões que fazem parte da dinâmica das relações sociais, como a legalização do aborto, o homossexualismo e as noções de hierarquia social.

Os resultados da incursão nas opiniões, atitudes e práticas cotidianas do brasileiro revelaram posicionamentos que apontam na direção de uma sociedade um tanto conservadora. Os dados mostraram que o comportamento social conservador não se restringe a uma escolha política eleitoral em particular. Pode-se dizer que as opiniões e as atitudes observadas em relação a essas questões quase independem do voto para presidente, e que a tendência apresentada pela maioria dos entrevistados é a de um posicionamento significativamente conservador. No entanto, outros elementos se destacaram junto às opiniões e atitudes apresentadas, como a dimensão dos valores religiosos e o status socioeconômico. Os temas abordados não se configuram como questões especificamente conjunturais, mas remetem às características da própria cultura brasileira. Dada esta complexidade, não se procurou explicar tais atitudes e opiniões, mas antes, mostrar algumas importantes relações entre o universo dos valores e das crenças, sua localização na estrutura socioeconômica e no contexto político e, assim, apontar algumas tendências do comportamento social do brasileiro.

Os temas tratados neste trabalho - o homossexualismo, o aborto, o papel da mulher e a hierarquia social - foram abordados junto a uma amostra nacional, no período após a eleição nacional de 2002, através da aplicação de um conjunto de questões. A Tabela 1 apresenta as questões aplicadas no questionário ${ }^{1}$.

\footnotetext{
${ }^{1}$ Vale destacar que foram considerados na análise dos dados apenas os casos de respostas válidas, ou seja, os casos "não respondeu" e "não sabe" foram excluídos e somados aos casos perdidos (missing cases). Esse procedimento foi tomado considerando-se que não há implicações para a análise que aqui se propõe.
} 


\section{Tabela 1}

\section{Temas e Questões utilizadas, ESEB 2002}

Temas

Homossexualismo

\section{Aborto e Papel da Mulher}

Hierarquia Social

\section{Perguntas}

Na opinião do(a) Sr(a)., os homossexuais são...

Pessoas como quaisquer outras,

Pessoas que nasceram com esse problema e por isso devem ser aceitas ou São pessoas com comportamento errado?

Vou ler outras frases e para cada frase eu gostaria que o(a) $\mathrm{Sr}(a)$. dissesse se concorda muito, concorda um pouco, discorda um pouco ou discorda muito ${ }^{2}$.

Um programa de televisão que defende o casamento de homem com homem e mulher com mulher deve ser proibido.

Com qual dessas frases o(a) $\mathrm{Sr}(a)$. concorda mais: ...

$\mathrm{O}$ aborto deve ser proibido em qualquer situação.

O aborto deve ser permitido se a mulher ficar grávida por causa de estupro. Ou

O aborto deve ser permitido em qualquer situação.

Na sua opinião:

Os homens devem dividir com as mulheres o trabalho de cuidar da casa e dos filhos ou

Essa é uma responsabilidade da mulher?

Se uma mulher apanha do marido, ela deve:

Dar queixa na polícia.

Separar-se do marido, mas não dar queixa. Ou

Não fazer nada para não desmanchar a família?

Dar queixa e separar-se do marido.

Os moradores de um prédio ou edifício dizem para os porteiros e empregadas domésticas que eles podem usar o elevador social, o que o(a) $\mathrm{Sr}(a)$. acha que os empregados do prédio deveriam fazer...

Eles deveriam usar o elevador social ou

Eles deveriam continuar usando o elevador de serviço?

O empregado trata o patrão de senhor, mas o patrão diz ao empregado que pode ser tratado de você, o que o(a) $\operatorname{Sr}(a)$. acha que o empregado deveria fazer?

Ele deveria continuar chamando o patrão por senhor ou

o empregado deveria passar a chamar o patrão por você?

O patrão diz ao empregado que ele pode tomar banho na piscina do edifício. O que o(a) $\operatorname{Sr}(a)$. acha que o empregado deveria fazer:

O empregado deveria agradecer e não deveria tomar banho na piscina ou o empregado deveria tomar banho na piscina?

Fonte: ESEB 2002

2 A alternativa: "nem discorda, nem concorda" foi aceita como espontânea, não foi lida pelo entrevistador. 
Sobre o homossexualismo, religião e voto

Os dados do ESEB 2002 sugerem que o homossexualismo ainda é visto por parte da sociedade brasileira como uma doença ou problema e, por esta razão, deve ser aceito. Esta é a postura da maioria dos entrevistados em relação à questão da homossexualidade, pautados por certa tolerância em âmbitos específicos. Mas essa tolerância não é verificada, por exemplo, quando se trata de ver a defesa do casamento de homossexuais na TV. Parte significativa dos entrevistados é a favor da proibição de programas de TV que defendam o casamento entre pessoas do mesmo sexo, seja entre homens ou entre mulheres. Mesmo entre os entrevistados que opinaram que os homossexuais são pessoas como outras quaisquer, verifica-se também a postura favorável à censura a um programa de TV que propague a união entre homossexuais.

Tabela 2

Opinião sobre Homossexuais

\begin{tabular}{rcc}
\hline \hline & $\%$ & $\mathbf{n}$ \\
Pessoas como quaisquer outras & 29,3 & 342 \\
Pessoas que nasceram com problemas e devem ser aceitas & 37,3 & 437 \\
Pessoas com comportamento errado & 33,4 & 391 \\
\hline Total & 100 & 1170 \\
\hline \hline
\end{tabular}

Fonte: ESEB 2002

Pergunta: Na opinião do(a) $\operatorname{Sr}(a)$., os homossexuais são...

Tabela 3

Opinião sobre Proibição de Programa de TV que Defende o Casamento entre Homossexuais

\begin{tabular}{rcc}
\hline \hline & $\%$ & $\mathbf{n}$ \\
Discorda Muito & 23,8 & 587 \\
Discorda um Pouco & 11,8 & 292 \\
Nem concorda nem discorda & 0,9 & 23 \\
Concorda um Pouco & 8,6 & 212 \\
Concorda Muito & $\mathbf{5 4 , 9}$ & $\mathbf{1 3 5 3}$ \\
\hline Total & 100 & 2467 \\
\hline
\end{tabular}

Fonte: ESEB 2002

Pergunta: Um programa de televisão que defende o casamento de homem com homem e mulher com mulher deve ser proibido 


\section{Tabela 4}

\section{Opiniões sobre Homossexualismo e sobre Proibição de Programa de TV que Defende o Casamento entre Homossexuais (\%)}

\begin{tabular}{|c|c|c|c|c|c|c|}
\hline $\begin{array}{l}\text { Na opinião do(a) Sr(a)., os } \\
\text { homossexuais são... }\end{array}$ & $\begin{array}{l}\text { Discorda } \\
\text { muito }\end{array}$ & $\begin{array}{l}\text { Discorda } \\
\text { um pouco }\end{array}$ & $\begin{array}{c}\text { Nem } \\
\text { concorda } \\
\text { nem } \\
\text { discorda }\end{array}$ & $\begin{array}{l}\text { Concorda } \\
\text { um pouco }\end{array}$ & $\begin{array}{l}\text { Concorda } \\
\text { muito }\end{array}$ & Total \\
\hline $\begin{array}{r}\text { Pessoas como quaisquer } \\
\text { outras }\end{array}$ & 40,5 & 21,3 & 3,0 & 8,0 & 27,2 & 100 \\
\hline $\begin{array}{r}\text { Pessoas que nasceram } \\
\text { com problemas e devem } \\
\text { ser aceitas }\end{array}$ & 22,2 & 11,3 & 0,7 & 11,8 & 53,9 & 100 \\
\hline $\begin{array}{l}\text { Pessoas com } \\
\text { comportamento errado }\end{array}$ & 17,0 & 3,9 & 0 & 6,7 & 72,5 & 100 \\
\hline
\end{tabular}

Qui-quadrado observado 182.185 significativo para o nível de $p<.000$

Fonte: ESEB 2002

Pergunta: Um programa de televisão que defende o casamento de homem com homem e mulher com mulher deve ser proibido

O dado mais interessante ou curioso desses resultados, não tão surpreendente dadas as manifestações comuns de intolerância em nossa sociedade ${ }^{3}$, aparece quando investigamos a caracterização socioeconômica e demográfica dessa maioria considerada intolerante. Ali se verifica quem são aqueles que até toleram os homossexuais mas que "não querem vê-los por aí se casando como pessoas como outras quaisquer"4.

\footnotetext{
${ }^{3}$ Mencionem-se os tristes episódios de violência que têm sofrido os homossexuais, como o caso do adestrador de cães, Edson Neris da Silva, que foi espancado e morto "por parecer homossexual". KAHN, Túlio, $O$ ataque careca. Folha de S. Paulo, 14 de fevereiro de 2000, p. 1-3. Folha de S. Paulo, 27 de janeiro de 1998, 130 homossexuais foram mortos em 97. FRANCISCO, Luiz, Discriminação: Brasil lidera crime contra homossexual. Folha de S. Paulo, 04 de abril de 2000.

${ }^{4}$ DIMENSTEIN, Gilberto. Jardim dos gays. Folha de S. Paulo, 10 de julho de 2002, p. C2.
} 
$\mathrm{Na}$ questão acerca da opinião sobre os homossexuais, a variável escolaridade parece ser um elemento de diferenciação entre grupos. Na relação entre estas duas variáveis, opinião sobre o homossexualismo e escolarização, verificou-se que, com o aumento do grau de instrução, a tendência a considerar os homossexuais como "pessoas como quaisquer outras" é maior. Esta tendência não foi observada na questão sobre a proibição de um programa que defenda o casamento entre homossexuais, na qual mesmo aqueles que se encontram na faixa de escolaridade média concordam muito com a censura de programas que propaguem a união entre pessoas do mesmo sexo. Somente na faixa de escolaridade superior é que há um maior número de pessoas contrárias a esta proibição.

Fenômeno semelhante ocorre na caracterização social através da renda familiar. As posturas são distintas conforme a variação da renda familiar no que diz respeito à opinião sobre os homossexuais e no que se refere à sua união. $\mathrm{Na}$ primeira questão mencionada, à medida em que se verifica um aumento da renda, há uma diminuição do número de repostas que apontam o homossexualismo como um problema e também daquelas que o reconhecem como um comportamento errado. Por outro lado, a opinião de que os homossexuais "são pessoas como quaisquer outras" é mais significativa. Já na pergunta sobre a exibição de um programa de TV que defende o casamento entre homossexuais, as opiniões são mais conservadoras e quase independem da renda de quem responde. Somente os $36,8 \%$ dos entrevistados com renda superior a treze salários mínimos (mais de $\mathrm{R} \$$ $2.700,00$ reais) discordam da proibição destes programas. A opinião da maioria dos entrevistados nas outras faixas de renda é a de que se deve proibir a veiculação de programas com este posicionamento.

Em relação à idade, há uma diferenciação nos posicionamentos somente no que diz respeito à opinião sobre os homossexuais: os jovens tendem a apresentar uma postura menos conservadora, enquanto a tendência entre o público adulto e de mais idade segue na direção oposta - o homossexualismo é apontado como um desvio de comportamento ou como um problema congênito. Mas, na questão sobre a proibição de programa de TV, a opinião de censura independe da faixa etária e a maioria é significativamente favorável à proibição. 
NISHIMURA, Kátia M. Conservadorismo social:...

Tabela 5

Opinião sobre os Homossexuais por Escolaridade, Renda e Idade (\%)

\begin{tabular}{|c|c|c|c|c|}
\hline & $\begin{array}{r}\text { “Pessoas como } \\
\text { quaisquer } \\
\text { outras" }\end{array}$ & $\begin{array}{r}\text { 'Pessoas que } \\
\text { nasceram com } \\
\text { problemas e devem } \\
\text { ser aceitas" } \\
\end{array}$ & $\begin{array}{r}\text { "Pessoas com } \\
\text { comportamento } \\
\text { errado" }\end{array}$ & Total \\
\hline Escolaridade & & & & Total \\
\hline Sem instrução & 12,8 & 22,1 & 65,1 & 100 \\
\hline Até $4^{\mathrm{a}}$. série & 14,9 & 41,1 & 44,0 & 100 \\
\hline De $5^{\mathrm{a}}$ a $8^{\mathrm{a}}$. série & 25,5 & 44,4 & 30,0 & 100 \\
\hline $2^{\circ}$.grau & 39,7 & 36,8 & 23,5 & 100 \\
\hline Superior ou mais & 49,0 & 27,5 & 23,5 & 100 \\
\hline \multicolumn{5}{|c|}{ Qui-quadrado 131.726 significativo para o nível de $p<.000$} \\
\hline Renda Mensal Familiar & & & & Total \\
\hline Sem Renda & 28,6 & 35,7 & 35,7 & 100 \\
\hline Até $1 \mathrm{SM}$ & 19,2 & 29,1 & 51,7 & 100 \\
\hline De mais de 1 a 4 SM & 24,5 & 41,7 & 33,7 & 100 \\
\hline De mais de 4 a $7 \mathrm{SM}$ & 24,5 & 42,9 & 32,5 & 100 \\
\hline De mais de 7 a $10 \mathrm{SM}$ & 38,0 & 33,1 & 28,9 & 100 \\
\hline De mais de 10 a $13 \mathrm{SM}$ & 51,7 & 27,6 & 20,7 & 100 \\
\hline Mais de $13 \mathrm{SM}$ & 48,4 & 33,7 & 17,9 & 100 \\
\hline \multicolumn{5}{|c|}{ Qui-quadrado 62.851 significativo para o nível de $p<.000$} \\
\hline Idade & & & & Total \\
\hline De 16 a 24 anos & 40,0 & 36,9 & 23,1 & 100 \\
\hline De 25 a 34 anos & 39,4 & 30,3 & 30,3 & 100 \\
\hline De 35 a 44 anos & 24,4 & 38,9 & 36,7 & 100 \\
\hline De 45 a 59 anos & 22,0 & 43,6 & 34,4 & 100 \\
\hline De 60 anos ou mais & 15,8 & 38,0 & 46,2 & 100 \\
\hline
\end{tabular}

Qui-quadrado 57.687 significativo para o nível de $p<.000$

Fonte: ESEB 2002 
OPINIÃO PÚBLICA, Campinas, Vol. X, no 2, Outubro, 2004, p. 339-367

Tabela 6

Opinião sobre a Proibição de Programa de TV que defende o casamento entre Homossexuais, por Renda, Escolaridade e Idade (\%)

\begin{tabular}{|c|c|c|c|c|c|c|}
\hline Renda Mensal Familiar & $\begin{array}{l}\text { Discorda } \\
\text { muito }\end{array}$ & $\begin{array}{l}\text { Discorda } \\
\text { um pouco }\end{array}$ & $\begin{array}{c}\text { Nem } \\
\text { concorda } \\
\text { nem } \\
\text { discorda } \\
\end{array}$ & $\begin{array}{l}\text { Concorda } \\
\text { um pouco }\end{array}$ & $\begin{array}{l}\text { Concorda } \\
\text { muito }\end{array}$ & Total \\
\hline Sem Renda & 33,3 & 7,7 & 0 & 5,1 & 53,8 & 100 \\
\hline Até $1 \mathrm{SM}$ & 21,6 & 8,2 & 0 & 7,5 & 62,7 & 100 \\
\hline De mais de 1 a $4 \mathrm{SM}$ & 21,4 & 9,6 & 0,6 & 8,8 & 59,6 & 100 \\
\hline De mais de 4 a $7 \mathrm{SM}$ & 19,8 & 15,6 & 0,3 & 6,6 & 57,8 & 100 \\
\hline De mais de 7 a $10 \mathrm{SM}$ & 28,5 & 14,2 & 3,2 & 7,9 & 46,2 & 100 \\
\hline De mais de 10 a $13 \mathrm{SM}$ & 30,0 & 13,3 & 1,7 & 6,7 & 48,3 & 100 \\
\hline Mais de $13 \mathrm{SM}$ & 36,8 & 20,4 & 0 & 8,0 & 34,8 & 100 \\
\hline \multicolumn{7}{|c|}{ Qui-quadrado 102.967 significativo para o nível de $p<.000$} \\
\hline Escolaridade & $\begin{array}{c}\text { Discorda } \\
\text { muito }\end{array}$ & $\begin{array}{l}\text { Discorda } \\
\text { um pouco }\end{array}$ & $\begin{array}{c}\text { Nem } \\
\text { concorda } \\
\text { nem } \\
\text { discorda }\end{array}$ & $\begin{array}{l}\text { Concorda } \\
\text { um pouco }\end{array}$ & $\begin{array}{l}\text { Concorda } \\
\text { muito }\end{array}$ & Total \\
\hline Sem instrução & 15,5 & 3,2 & 0 & 2,1 & 79,1 & 100 \\
\hline Até $4^{\mathrm{a}}$. série & 17,0 & 5,4 & 0,8 & 8,6 & 68,3 & 100 \\
\hline De $5^{\mathrm{a}}$ a $8^{\mathrm{a}}$. série & 22,4 & 12,2 & 0,2 & 8,3 & 57,0 & 100 \\
\hline $2^{\circ}$. grau & 26,3 & 17,9 & 1,4 & 10,3 & 44,1 & 100 \\
\hline Superior ou mais & 39,2 & 14,7 & 2,2 & 8,5 & 35,4 & 100 \\
\hline \multicolumn{7}{|c|}{ Qui-quadrado 218.418 significativo para o nível de $p<.000$} \\
\hline Idade & $\begin{array}{l}\text { Discorda } \\
\text { muito }\end{array}$ & $\begin{array}{l}\text { Discorda } \\
\text { um pouco }\end{array}$ & $\begin{array}{c}\text { Nem } \\
\text { concorda } \\
\text { nem } \\
\text { discorda }\end{array}$ & $\begin{array}{l}\text { Concorda } \\
\text { um pouco }\end{array}$ & $\begin{array}{c}\text { Concorda } \\
\text { muito }\end{array}$ & Total \\
\hline De 16 a 24 anos & 28,5 & 18,4 & 0,6 & 12,0 & 40,5 & 100 \\
\hline De 25 a 34 anos & 28,5 & 14,0 & 2,4 & 8,7 & 46,4 & 100 \\
\hline De 35 a 44 anos & 25,2 & 11,4 & 0,5 & 8,8 & 54,1 & 100 \\
\hline De 45 a 59 anos & 20,8 & 7,5 & 0,6 & 7,3 & 63,8 & 100 \\
\hline De 60 anos ou mais & 11,9 & 6,6 & 0,3 & 5,4 & 75,8 & 100 \\
\hline
\end{tabular}

Qui-quadrado 154.305 significativo para o nível de $p<.000$

Fonte: ESEB 2002

Pergunta: Um programa de televisão que defende o casamento de homem com homem e mulher com mulher deve ser proibido 
O que os dados mostram é que a aceitação do homossexualismo está longe de ser um fato. Por mais que existam respostas favoráveis a aceitá-los como "pessoas como outras quaisquer", parcela significativa dos entrevistados não permite que a união de pessoas do mesmo sexo se propague como algo comum. Essas questões são também permeadas por valores morais de fundo religioso: a maioria dos entrevistados que declara ter uma religião, sejam católicos, evangélicos pentecostais ou não-pentecostais, aponta o homossexualismo como um desvio de comportamento ou como um problema. E, com exceção dos espíritas kardecistas e dos budistas, a maioria dos entrevistados é significativamente favorável à proibição de um programa de TV que defenda o casamento entre homossexuais. Já entre os ateus, encontramos os posicionamentos menos conservadores: a maioria dos entrevistados discordam muito da proibição de programas que defendam o casamento entre pessoas do mesmo sexo e também apresentam posturas mais favoráveis a aceitação do homossexualismo. (ver o artigo de Simone Bohn neste número de OP)

A Igreja Católica tem, de fato, procurado definir orientações sobre este tema. Após uma manifestação de homossexuais próxima ao Coliseu em Roma, o Papa João Paulo II afirmou que o homossexualismo "vai contra as leis da natureza" e é "uma ofensa aos cristãos", embora neste mesmo pronunciamento, a autoridade religiosa tenha alertado sobre a discriminação contra os homossexuais, afirmando que "devem ser tratados com respeito, compaixão e delicadeza" 5 . Parece ser esta também a orientação seguida por grande parte dos católicos entrevistados que disseram considerar os homossexuais "pessoas que nasceram com esse problema e por isso devem ser aceitas". A Tabela 7 mostra que os católicos foram os que apresentaram esta opinião em maior proporção. Além disso, apesar do fenômeno evangélico pentecostal dos últimos anos, a sociedade brasileira é expressivamente católica - quase $70 \%$ dos entrevistados do ESEB.

\footnotetext{
5 "O papa João Paulo II criticou ontem a manifestação de homossexuais que aconteceu no sábado em Roma. Chamada de "World Gay Pride 2000", a parada reuniu cerca de 70 mil pessoas nas ruas em torno do Coliseu, segundo avaliação da polícia". Folha de S. Paulo, 10 de julho de 2000. Igreja: João Paulo /l diz que homossexualismo é anomalia. Papa critica manifestação de homossexuais na capital italiana.
} 
Mariano destaca que mesmo as igrejas neo-pentecostais ${ }^{6}$, apesar de mais liberais, estabelecem orientações tipicamente puritanas e moralistas contra o homossexualismo, a pornografia, as drogas, a assistência a programas de TV que exploram a sexualidade e a violência (MARIANO, 1999, p. 210). A prática do homossexualismo é condenada tanto por católicos como pelos evangélicos pentecostais, que responsabilizam homens e mulheres homossexuais pelo surgimento de doenças como a AIDS. Esta, segundo Machado, é interpretada por estes grupos religiosos como castigo de Deus (MACHADO, 1996, p. 175). Através dos sermões e das pregações de religiosos, são disseminadas concepções como a da relação entre atividade sexual e procriação e, segundo tais concepções, as relações entre pessoas do mesmo sexo são contra a própria natureza. Em algumas denominações pentecostais, não somente se condena a prática homossexual, como também divulga-se amplamente a "cura de pessoas com problemas desta natureza". Os depoimentos, uma espécie de testemunho público, de pessoas que abandonaram esta prática é bastante comum. Machado destaca que algumas denominações pentecostais aceitam ex-homossexuais em suas fileiras como parte das estratégias para aumentar sua capacidade de atração, pois esta aceitação poderia ser vista também como uma demonstração de maior tolerância (MACHADO, 1996, p. 177).

\footnotetext{
${ }^{6}$ Segundo Pierucci, as mais representativas em tamanho e visibilidade são as seguintes: Igreja de Nova Vida, fundada em 1960; Comunidade Evangélica Sara Nossa Terra, fundada em 1976; Igreja Universal do Reino de Deus, fundada em 1977; Igreja Internacional da Graça de Deus, fundada em 1980 e Renascer em Cristo, fundada em 1986 (PIERUCCI, 2000, p. 288-289).
} 
Tabela 7

Opinião sobre Homossexualismo e Opinião sobre Programa de TV que defende o casamento entre homossexuais por Religião (\%)

\begin{tabular}{|c|c|c|c|c|c|c|c|c|c|c|}
\hline \multirow[t]{2}{*}{ Religião } & \multicolumn{6}{|c|}{$\begin{array}{c}\text { Proibição de um programa de TV que } \\
\text { defenda o casamento entre homossexuais }\end{array}$} & \multicolumn{4}{|c|}{ Opinião sobre homossexuais } \\
\hline & $D M$ & $D P$ & $\begin{array}{l}N D \\
N C\end{array}$ & $C P$ & $C M$ & Total & $\begin{array}{r}\text { Pessoas } \\
\text { como } \\
\text { quais- } \\
\text { quer } \\
\text { outras }\end{array}$ & $\begin{array}{r}\text { Pessoas } \\
\text { que } \\
\text { nasceram } \\
\text { com esse } \\
\text { problema e } \\
\text { devem ser } \\
\text { aceitas }\end{array}$ & $\begin{array}{r}\text { Pessoas } \\
\text { com } \\
\text { comporta } \\
\text { mento } \\
\text { errado }\end{array}$ & Total \\
\hline $\begin{array}{r}\text { Mórmon, } \\
\text { Adventista, } \\
\text { Testemunha } \\
\text { de Jeová }\end{array}$ & 19,6 & 15,7 & 0 & 2,0 & 62,7 & 100 & 18,2 & 22,7 & 59,1 & 100 \\
\hline $\begin{array}{r}\text { Evangélica } \\
\text { Pentecostal }\end{array}$ & 13,6 & 3,8 & 1,0 & 4,5 & 77,0 & 100 & 12,0 & 24,8 & 63,2 & 100 \\
\hline $\begin{array}{r}\text { Evangélica } \\
\text { não- } \\
\text { pentecostal }\end{array}$ & 18,8 & 5,9 & 7,1 & 8,2 & 60,0 & 100 & 27,9 & 16,3 & 55,8 & 100 \\
\hline Candomblé & 27,3 & 18,2 & 0 & 0 & 54,5 & 100 & 60,0 & 0 & 40,0 & 100 \\
\hline Umbanda & 12,5 & 25,0 & 0 & 12,5 & 50,0 & 100 & 60,0 & 0 & 40,0 & 100 \\
\hline $\begin{array}{r}\text { Espírita } \\
\text { Kardecista }\end{array}$ & 42,5 & 20,5 & 0 & 9,6 & 27,4 & 100 & 47,2 & 36,1 & 16,7 & 100 \\
\hline $\begin{array}{r}\text { Seisho-no-iê, } \\
\text { Messiânica }\end{array}$ & 28,6 & 42,9 & 0 & 14,3 & 14,3 & 100 & & & & \\
\hline Católica & 23,5 & 12,8 & 0,7 & 9,7 & 53,3 & 100 & 28,8 & 42,1 & 29,1 & 100 \\
\hline Budista & 75,0 & 12,5 & 0 & 0 & 12,5 & 100 & 100 & & & 100 \\
\hline $\begin{array}{r}\text { Santo } \\
\text { Daime, } \\
\text { Esotérica, } \\
\text { Outras }\end{array}$ & 29,0 & 3,2 & 0 & 3,2 & 64,5 & 100 & 23,1 & 30,8 & 46,2 & 100 \\
\hline $\begin{array}{r}\text { Não tem } \\
\text { religião }\end{array}$ & 36,2 & 12,4 & 0,6 & 7,9 & 42,9 & 100 & 46,1 & 29,2 & 24,7 & 100 \\
\hline Ateu & 100 & 0 & 0 & 0 & 0 & 100 & 50,0 & 50,0 & 0 & 100 \\
\hline \multicolumn{7}{|c|}{ Qui-quadrado 185.783 significativo ao nível de $p<.000$} & \multicolumn{4}{|c|}{$\begin{array}{l}\text { Qui-quadrado } 109.199 \text { significativo ao níve } \\
\text { de } p<.000\end{array}$} \\
\hline
\end{tabular}

Fonte: ESEB 2002 
A religião tem impacto expressivo na dimensão dos valores que orientam as atitudes e práticas sociais cotidianas e, nesse sentido, destaca-se também para compreender a relação entre as opiniões sobre o homossexualismo e o voto na eleição presidencial de 2002. A Tabela 8 apresenta como os adeptos das várias religiões votaram em $2002^{7}$. É o voto dos evangélicos pentecostais e nãopentecostais $^{8}$ que se destaca, tendo a sua maioria votado no candidato do PSB à presidência, Anthony Garotinho? .

Essa associação é clara. Os dados mostram que os evangélicos pentecostais e não-pentecostais apresentam posicionamentos conservadores no que diz respeito tanto ao homossexualismo quanto à propagação de idéias que defendam o casamento entre pessoas do mesmo sexo e que estão associados ao voto em Garotinho.

O candidato Garotinho deixou clara durante toda a campanha eleitoral - em entrevistas, programas de TV e mesmo em reuniões com lideranças das igrejas evangélicas - sua posição contrária em relação ao casamento entre pessoas do mesmo sexo e à possibilidade de adoção por casais homossexuais ${ }^{10}$. Pastores e membros das igrejas evangélicas, que apoiaram sua candidatura pedindo votos em suas pregações, reforçavam a concepção imoral da união homossexual ${ }^{11}$. Garotinho dizia ser contra a união entre os homossexuais e não contra eles enquanto pessoas e afirmava não mudar sua opinião para ganhar votos. Em 2001, quando era governador do estado do Rio de Janeiro, Garotinho sancionou uma lei contra a homofobia e deu a seguinte declaração: "Uma coisa é o homossexualismo, outra coisa é o homossexual. Uma coisa é o pecador, outra é o pecado. Sou contra o homossexualismo, abertamente contra". Mais tarde, em 2002, por ocasião da campanha eleitoral, apresentou uma postura mais radical "Eu, como cristão, sou

\footnotetext{
7 Foram excluídas da variável Intenção de voto as respostas: "não sabe", "justificou o voto", "não respondeu", "voto nulo", "não votou", "voto em branco" e "não lembra", que foram incorporadas aos casos perdidos (missing cases).

${ }^{8}$ Segundo Pierucci, as missões evangélicas no Brasil são mais antigas, chegaram aqui por volta do início do século XIX. As denominações clássicas do protestantismo são: luteranos, anglicanos ou episcopais, metodistas, presbiterianos, congregacionalistas e batistas (PIERUCCI, 2000, p. 286.287).

9 O candidato do PT, Lula, foi o mais votado em quase todos os grupos religiosos, com exceção dos evangélicos pentecostais e não-pentecostais e do grupo no qual localizam-se os adeptos do Santo Daime, Esotérica e outros. Ciro Gomes, candidato da coligação PDT.PTB, foi o mais votado entre aqueles que não têm religião. José Serra, do PSDB, recebeu mais votos entre os adeptos do Santo Daime, Esotérica e outros. E o candidato do PSTU, José Maria, teve o seu maior número de votos entre os católicos.

${ }^{10}$ Folha de S. Paulo, 07 de junho de 2002, Garotinho diz que, eleito, veta união de homossexuais. p. A6.

11 ANTENORE, Armando. Pastor prega voto evangélico contra 'raça gay'. Caderno Especial Folha de S. Paulo, 29 de setembro de 2002, p. 09. LEONEL, Vange. O fruto da ignorância. Revista da Folha, 20 de outubro de 2002, p. 56. BERABA, Marcelo, Influência da Universal preocupa Igreja Católica. Folha de S. Paulo, 28 de outubro de 2002, Caderno Especial 2, Eleições 2002.
} 
NISHIMURA, Kátia M. Conservadorismo social:...

contra o casamento entre pessoas do mesmo sexo e a adoção de crianças por casais gays"12.

A maioria dos entrevistados que votaram em Lula (PT), José Serra (PSDB) e Ciro Gomes (coligação PDT.PTB) acreditam que o homossexualismo é um problema e, por essa razão, os homossexuais devem ser aceitos. Os eleitores do candidato do PSTU polarizaram-se entre considerar os homossexuais como pessoas como quaisquer outras e considerá-los pessoas com desvio de comportamento. $\mathrm{Na}$ questão sobre a proibição de um programa de TV que defende o casamento entre pessoas do mesmo sexo, se destacaram por discordar desta medida em proporção significativa. (Tabela 9)

\section{Tabela 8}

Religião e Voto na eleição presidencial de 2002

\begin{tabular}{|c|c|c|c|c|c|c|}
\hline Religiões & Lula & Ciro Gomes & $\begin{array}{l}\text { José } \\
\text { Serra }\end{array}$ & Garotinho & $\begin{array}{l}\text { José } \\
\text { Maria }\end{array}$ & $\begin{array}{l}\text { Total \% } \\
(n=2013) \\
\end{array}$ \\
\hline $\begin{array}{l}\text { Mórmon, Adventista, } \\
\text { Testemunha de Jeová }\end{array}$ & 69,7 & 6,1 & 21,2 & 3,0 & & 100 \\
\hline Evangélica Pentecostal & 29,8 & 4,0 & 12,9 & 52,9 & 0,4 & 100 \\
\hline Evangélica não-pentecostal & 26,2 & 6,2 & 23,1 & 43,1 & 1,5 & 100 \\
\hline Candomblé & 90,9 & & 9,1 & & & 100 \\
\hline Umbanda & 71,4 & & 14,3 & 14,3 & & 100 \\
\hline Espírita Kardecista & 49,2 & 10,8 & 32,3 & 7,7 & & 100 \\
\hline Seisho-no-iê, Messiânica & 66,7 & & 33,3 & & & 100 \\
\hline Católica & 57,5 & 10,9 & 25,5 & 5,8 & 0,3 & 100 \\
\hline Budista & 66,7 & 11,1 & 22,2 & & & 100 \\
\hline $\begin{array}{r}\text { Santo Daime, Esotérica, } \\
\text { Outras }\end{array}$ & 30,4 & & 39,1 & 30,4 & & 100 \\
\hline Não tem religião & 58,7 & 14,3 & 13,5 & 13,5 & & 100 \\
\hline Ateu & & & 100 & & & 100 \\
\hline
\end{tabular}

Fonte: ESEB 2002

\footnotetext{
12 MOTT, Luiz. Os presidenciáveis e os homossexuais. Folha de S. Paulo, Opinião, 26 de setembro de 2002, p. A3. LEONEL, Vange. Vice Mulher. Revista da Folha, 16 de junho de 2002, p. 41. Folha de S. Paulo, 20 de maio de 2002, Geografia do preconceito, p. A4. Folha de S. Paulo, 18 de maio de 2002. "Não sou frango", diz Garotinho, que é contrário à união civil de homossexuais, p. C4.
} 
OPINIÃO PÚBLICA, Campinas, Vol. X, no 2, Outubro, 2004, p. 339-367

Tabela 9

Opinião sobre Homossexualismo, opinião sobre programa de TV que defende o casamento entre homossexuais e Voto em 2002

\begin{tabular}{|c|c|c|c|c|c|c|}
\hline $\begin{array}{c}\text { Na opinião do(a) Sr(a)., os } \\
\text { homossexuais são... }\end{array}$ & Lula & $\begin{array}{c}\text { Ciro } \\
\text { Gomes } \\
\end{array}$ & José Serra & Garotinho & $\begin{array}{l}\text { José } \\
\text { Maria } \\
\end{array}$ & Total \\
\hline $\begin{array}{r}\text { Pessoas como quaisquer } \\
\text { outras }\end{array}$ & 32,6 & 33,7 & 27,3 & 15,4 & 50,0 & 100 \\
\hline $\begin{array}{r}\text { Pessoas que nasceram com } \\
\text { problemas e devem ser } \\
\text { aceitas }\end{array}$ & 40,0 & 37,8 & 43,7 & 28,5 & & 100 \\
\hline $\begin{array}{r}\text { Pessoas com } \\
\text { comportamento errado } \\
\end{array}$ & 27,3 & 28,6 & 29,0 & 56,1 & 50,0 & 100 \\
\hline Qui-quadrado 45.464 significativ & go níve & $<.000$ & & & & \\
\hline $\begin{array}{l}\text { Um programa de televisão que } \\
\text { defende o casamento de } \\
\text { homem com homem e mulher } \\
\text { com mulher deve ser proibido }\end{array}$ & Lula & $\begin{array}{l}\text { Ciro } \\
\text { Gomes }\end{array}$ & José Serra & Garotinho & $\begin{array}{l}\text { José } \\
\text { Maria }\end{array}$ & Total \\
\hline Discorda Muito & 25,5 & 24,1 & 23,5 & 14,2 & 83,5 & 100 \\
\hline Discorda um Pouco & 14,4 & 13,3 & 11,8 & 6,2 & & 100 \\
\hline Nem concorda nem discorda & 0,7 & 2,1 & 1,9 & 0,4 & & 100 \\
\hline Concorda um Pouco & 10,2 & 5,1 & 7,5 & 7,7 & & 100 \\
\hline Concorda Muito & 49,2 & 55,4 & 55,3 & 71,5 & 16,7 & 100 \\
\hline
\end{tabular}

Fonte: ESEB 2002

Sobre o aborto e o papel da mulher

Os dados do ESEB mostram que, independentemente do status socioeconômico e da faixa etária, a maioria expressiva de homens e mulheres concorda que o trabalho de cuidar dos filhos e da casa deve ser dividido. A maioria também posiciona-se favoravelmente à atitude da mulher, agredida pelo marido, de dar queixa à polícia. Estas são questões cujos posicionamentos não são dependentes da escolha política eleitoral: a maioria dos eleitores de Lula, José Serra, Ciro Gomes e de Anthony Garotinho concorda com essa atitude. Entre os eleitores de Garotinho concentram-se as opiniões de que a preservação da família deve prevalecer em uma situação de agressão à mulher $(12,1 \%)$ enquanto, entre os eleitores dos outros candidatos, esta porcentagem não passa de $8 \%$. Não é demais lembrar a vinculação da disparidade entre sexos e da posição de inferioridade social 
NISHIMURA, Kátia M. Conservadorismo social:...

da mulher ao universo dos valores tradicionalistas, especificamente, neste caso, do mundo evangélico (MACHADO, 1996). Novamente, é entre os eleitores do candidato do PSB que ocorrem as opiniões mais conservadoras e mais irredutíveis em relação à questão do aborto. Assim como nas posturas apresentadas em relação ao tema do homossexualismo no caso das opiniões dos eleitores de Garotinho, parece haver um peso significativo da dimensão religiosa dos valores morais entre os eleitores de Garotinho.

A Tabela 12 apresenta as opiniões dos entrevistados em relação ao tema do aborto. A opinião de que o aborto somente deve ser permitido em casos particulares, como no caso de uma gravidez provocada por estupro, é predominante; mesmo assim, a alternativa de que o aborto deveria ser proibido em qualquer situação foi apontada por parte significativa dos entrevistados.

Os dados mostram também que para esse conjunto de temas delineia-se um claro grupo mais conservador: os mais preocupados com a preservação dos valores familiares, que defendem a idéia de que a preservação da família sobrepõe-se à defesa da mulher e para quem o trabalho de cuidar dos filhos e da casa é uma tarefa que cabe estritamente à mulher são também os mais conservadores em relação à liberalização do aborto, afirmando-se favoráveis à sua proibição em qualquer circunstância.

Tabela 10

Opiniões e Atitudes em relação ao Papel da Mulher (\%)

\begin{tabular}{|c|c|c|c|}
\hline $\begin{array}{r}\text { Opinião sobre o trabalho de cuidar } \\
\text { da casa e dos filhos }\end{array}$ & $\begin{array}{c}\% \\
(n=2496) \\
\end{array}$ & $\begin{array}{r}\text { Atitude que uma mulher agredida } \\
\text { pelo marido deve ter } \\
\end{array}$ & $\begin{array}{c}\% \\
(n=2447) \\
\end{array}$ \\
\hline $\begin{array}{r}\text { Homens devem dividir este trabalho } \\
\text { com mulheres }\end{array}$ & 89,7 & Dar queixa na polícia & 58,7 \\
\hline \multirow[t]{3}{*}{$\begin{array}{l}\text { Este trabalho só é de } \\
\text { responsabilidade da mulher }\end{array}$} & 10,3 & $\begin{array}{r}\text { Separar-se do marido, mas não dar } \\
\text { queixa }\end{array}$ & 24,0 \\
\hline & & $\begin{array}{r}\text { Não fazer nada para não desmanchar } \\
\text { a família }\end{array}$ & 8,1 \\
\hline & & Dar queixa e separar-se do marido & 9,7 \\
\hline
\end{tabular}

Fonte: ESEB 2002 
OPINIÃO PÚBLICA, Campinas, Vol. X, no 2, Outubro, 2004, p. 339-367

Tabela 11

Opiniões e Atitudes em relação ao Papel da Mulher e Voto em 2002 (\%)

\begin{tabular}{|c|c|c|c|c|c|c|}
\hline Opiniões e Atitudes & Lula & $\begin{array}{c}\text { Ciro } \\
\text { Gomes } \\
\end{array}$ & $\begin{array}{l}\text { José } \\
\text { Serra }\end{array}$ & Garotinho & $\begin{array}{l}\text { José } \\
\text { Maria }\end{array}$ & $\begin{array}{c}\text { Total } \\
(\mathrm{n}=\mathbf{2 0 0 1 )} \\
\end{array}$ \\
\hline \multicolumn{7}{|l|}{$\begin{array}{l}\text { Opinião sobre o trabalho de } \\
\text { cuidar da casa e dos filhos }\end{array}$} \\
\hline $\begin{array}{r}\text { Homens devem dividir este } \\
\text { trabalho com mulheres }\end{array}$ & 91,1 & 94,4 & 90,2 & 87,7 & 100 & 100 \\
\hline $\begin{array}{l}\text { Este trabalho só é de } \\
\text { responsabilidade da mulher }\end{array}$ & 8,9 & 5,6 & 9,8 & 12,3 & & 100 \\
\hline \multicolumn{7}{|c|}{ Qui-quadrado 6.871 significativo ao nível de $p<.20$} \\
\hline \multicolumn{7}{|c|}{$\begin{array}{l}\text { Atitude que uma mulher } \\
\text { agredida pelo marido deve ter }\end{array}$} \\
\hline Dar queixa na polícia & 60,6 & 67,0 & 59,3 & 53,5 & 100 & 100 \\
\hline $\begin{array}{r}\text { Separar-se do marido, mas não } \\
\text { dar queixa }\end{array}$ & 23,1 & 19,4 & 24,2 & 26,6 & & 100 \\
\hline $\begin{array}{r}\text { Não fazer nada para não } \\
\text { desmanchar a família }\end{array}$ & 6,4 & 5,2 & 7,7 & 12,1 & & 100 \\
\hline $\begin{array}{r}\text { Dar queixa e separar-se do } \\
\text { marido } \\
\end{array}$ & 9,9 & 8,4 & 8,8 & 7,8 & & 100 \\
\hline
\end{tabular}

Fonte: ESEB 2002

Tabela 12

Opinião sobre o Aborto

\begin{tabular}{rc}
\hline \hline Com qual dessas frases o (a) Sr(a). concorda mais: & \% (n) \\
\hline O aborto deve ser proibido em qualquer situação & $37,4(907)$ \\
O aborto deve ser permitido se a mulher ficar grávida por causa de estupro & $\mathbf{5 1 , 0}(\mathbf{1 2 3 7})$ \\
O aborto deve ser permitido em qualquer situação & $11,5(280)$ \\
& Total \\
\hline \hline
\end{tabular}

Fonte: ESEB 2002 
NISHIMURA, Kátia M. Conservadorismo social:...

Tabela 13

Opinião sobre o Aborto e Papel da Mulher (\%)

\begin{tabular}{|c|c|c|c|c|}
\hline \multicolumn{5}{|c|}{ Opinião sobre o Aborto } \\
\hline $\begin{array}{r}\text { Opinião sobre o } \\
\text { trabalho de cuidar da } \\
\text { casa e dos filhos }\end{array}$ & $\begin{array}{r}\text { Deve ser proibido } \\
\text { em qualquer } \\
\text { situação }\end{array}$ & $\begin{array}{r}\text { Deve ser permitido } \\
\text { se a mulher } \\
\text { engravidou devido a } \\
\text { estupro }\end{array}$ & $\begin{array}{r}\text { Deve ser permitido } \\
\text { em qualquer } \\
\text { situação }\end{array}$ & Tota \\
\hline $\begin{array}{r}\text { Homens devem dividir } \\
\text { este trabalho com } \\
\text { mulheres }\end{array}$ & 35,9 & 53,3 & 10,8 & 100 \\
\hline $\begin{array}{r}\text { Este trabalho só é de } \\
\text { responsabilidade da } \\
\text { mulher }\end{array}$ & 51,5 & 31,2 & 17,3 & 100 \\
\hline \multicolumn{5}{|c|}{ Qui-quadrado 42192 significativo ao nível de $p<.000$} \\
\hline $\begin{array}{r}\text { Atitude que uma } \\
\text { mulher agredida pelo } \\
\text { marido deve ter }\end{array}$ & & & & 100 \\
\hline Dar queixa na polícia & 33,7 & 55,7 & 10,6 & 100 \\
\hline $\begin{array}{r}\text { Separar-se do marido, } \\
\text { mas não dar queixa }\end{array}$ & 41,0 & 44,7 & 14,4 & 100 \\
\hline $\begin{array}{r}\text { Não fazer nada para não } \\
\text { desmanchar a } \\
\text { família }\end{array}$ & 55,6 & 32,8 & 11,7 & 100 \\
\hline $\begin{array}{r}\text { Dar queixa e separar-se } \\
\text { do marido } \\
\end{array}$ & 31,5 & 57,3 & 11,2 & 100 \\
\hline
\end{tabular}

Fonte: ESEB 2002

A Tabela 14 mostra as opiniões de grupos religiosos sobre a questão do aborto. A opinião de que o aborto somente deve ser permitido em uma situação específica é compartilhada pela maioria dos entrevistados: católicos, evangélicos pentecostais e não-pentecostais, das religiões afro-brasileiras e também dos que declararam não ter religião. Já para os adeptos de religiões como os Mórmons, os Adventistas e Testemunhas de Jeová, o aborto deve ser proibido em qualquer situação.

O eleitorado de Garotinho destaca-se quanto a essa questão. É neste público que encontramos, comparativamente, o maior número de opiniões que apóiam à proibição do aborto em qualquer circunstância e a menor porcentagem de casos favoráveis à liberalização do aborto independentemente da situação. Os pentecostais têm uma trajetória de ativismo político essencialmente moralista e são conhecidos pela recusa em separar as questões políticas da moralidade privada. A participação do bloco evangélico suprapartidário nas comissões da Assembléia 
Constituinte de 1986, em que as questões morais estavam presentes, é emblemática desta trajetória. Neste bloco, que contava com um número substantivo de representantes das vertentes mais tradicionalistas evangélicas, os posicionamentos contrários à descriminalização do aborto, ao feminismo, ao homossexualismo, à pornografia, ao divórcio e às drogas foram preponderantes (PIERUCCI, 1989; MACHADO, 1996). Ainda que se trate de posicionamentos de lideranças políticas dentro de uma comunidade religiosa, não se pode ignorar ou menosprezar as formas de compromisso e assimilação dos valores da liderança religiosa por parte dos membros desta comunidade (MACHADO, 1996). A tendência apresentada pelos dados parece seguir neste sentido da assimilação dos valores das lideranças religiosas e do seu compartilhamento por parte da comunidade, pelo menos no que diz respeito às opiniões observadas. Se não se pode afirmar uma assimilação e adesão aos valores defendidos pelas lideranças religiosas ou políticas por parte da comunidade, a partir desses dados, pode-se dizer seguramente que eles indicam um terreno fértil a ser investigado.

Tabela 14

Opinião sobre o Aborto segundo a Religião (\%) Opinião sobre o Aborto

\begin{tabular}{|c|c|c|c|c|}
\hline \multicolumn{5}{|c|}{ Opinião sobre o Aborto } \\
\hline Religiões & $\begin{array}{r}\text { Deve ser proibido } \\
\text { em qualquer } \\
\text { situação }\end{array}$ & $\begin{array}{r}\text { Deve ser permitido se a } \\
\text { mulher engravidou devido } \\
\text { a estupro }\end{array}$ & $\begin{array}{r}\text { Deve ser permitido } \\
\text { em qualquer } \\
\text { situação }\end{array}$ & Tota \\
\hline $\begin{array}{r}\text { Mórmon, Adventista, } \\
\text { Testemunha de } \\
\text { Jeová } \\
\end{array}$ & 65,4 & 30,8 & 3,8 & 100 \\
\hline $\begin{array}{r}\text { Evangélica } \\
\text { Pentecostal }\end{array}$ & 46,8 & 47,1 & 6,1 & 100 \\
\hline $\begin{array}{r}\text { Evangélica não- } \\
\text { pentecostal }\end{array}$ & 32,1 & 58,3 & 9,5 & 100 \\
\hline Candomblé & 18,2 & 54,5 & 27,3 & 100 \\
\hline Umbanda & 33,3 & 66,7 & & 100 \\
\hline Espírita Kardecista & 21,9 & 64,4 & 13,7 & 100 \\
\hline $\begin{array}{r}\text { Seisho-no-iê, } \\
\text { Messiânica }\end{array}$ & 50,0 & & 50,0 & 100 \\
\hline Católica & 37,6 & 50,8 & 11,7 & 100 \\
\hline Budista & & 50,0 & 50,0 & 100 \\
\hline $\begin{array}{r}\text { Santo Daime, } \\
\text { Esotérica, Outras }\end{array}$ & 40,0 & 46,7 & 13,3 & 100 \\
\hline Não tem religião & 24,3 & 59,0 & 16,8 & 100 \\
\hline Ateu & & 1 & 1 & 100 \\
\hline Qui-quadrado $92.450 \mathrm{~s}$ & nificativo ao nível d & $e p<.000$ & & \\
\hline
\end{tabular}


Tabela 15

\section{Opinião sobre o Aborto e Voto em 2002 (\%)}

\begin{tabular}{|c|c|c|c|c|}
\hline \multicolumn{5}{|c|}{ Opinião sobre o Aborto } \\
\hline & $\begin{array}{r}\text { Deve ser proibido } \\
\text { em qualquer } \\
\text { situação }\end{array}$ & $\begin{array}{r}\text { Deve ser permitido } \\
\text { se a mulher } \\
\text { engravidou devido } \\
\text { a estupro }\end{array}$ & $\begin{array}{r}\text { Deve ser permitido } \\
\text { em qualquer } \\
\text { situação }\end{array}$ & Total \\
\hline Lula & 34,8 & 52,4 & 12,8 & 100 \\
\hline Ciro Gomes & 27,9 & 63,2 & 8,9 & 100 \\
\hline José Serra & 36,2 & 53,3 & 10,5 & 100 \\
\hline Garotinho & 45,1 & 48,2 & 6,7 & 100 \\
\hline José Maria & 50,0 & 50,0 & & 100 \\
\hline
\end{tabular}

Fonte: ESEB 2002

Há um outro elemento importante a destacar em relação aos posicionamentos sobre o aborto: os posicionamentos mais conservadores, que defendem a sua proibição em qualquer circunstância, localizam-se entre aqueles com mais idade, mais pobres e menos escolarizados. A opinião de que o aborto deve ser proibido de forma incondicional concentra-se na faixa dos 60 anos ou mais, entre aqueles que não têm renda ou com renda de até um salário mínimo e com muito pouca instrução, analfabetos ou que cursaram até a $4^{a}$. série do Ensino Fundamental. Quanto à opinião de que o aborto deve ser permitido em uma situação específica, apontada pela maioria dos entrevistados, é predominantemente encontrada tanto entre aqueles com menor renda e baixa escolaridade como entre os mais escolarizados e de maior renda. Esta postura também é a preponderante tanto entre os jovens como entre os adultos. 
Tabela 16

Opinião sobre o Aborto por Faixas de Renda, Escolaridade e Idade (\%)

\begin{tabular}{|c|c|c|c|c|}
\hline \multirow{2}{*}{$\begin{array}{l}\text { Dados } \\
\text { socioeconômicos } \\
\text { Renda Mensal Familiar }\end{array}$} & \multicolumn{4}{|c|}{ Opinião sobre o aborto } \\
\hline & $\begin{array}{r}\text { Deve ser } \\
\text { proibido em } \\
\text { qualquer } \\
\text { situação }\end{array}$ & $\begin{array}{r}\text { Deve ser permitido se } \\
\text { a mulher engravidou } \\
\text { devido a estupro }\end{array}$ & $\begin{array}{r}\text { Deve ser permitido em } \\
\text { qualquer situação }\end{array}$ & Total \\
\hline Sem Renda & 63,2 & 31,6 & 5,3 & 100 \\
\hline Até $1 \mathrm{SM}$ & 53,0 & 33,0 & 14,0 & 100 \\
\hline De mais de 1 a $4 \mathrm{SM}$ & 43,1 & 46,3 & 10,6 & 100 \\
\hline De mais de 4 a $7 \mathrm{SM}$ & 30,1 & 60,6 & 9,3 & 100 \\
\hline De mais de 7 a $10 \mathrm{SM}$ & 28,3 & 62,2 & 9,4 & 100 \\
\hline De mais de 10 a $13 \mathrm{SM}$ & 17,2 & 65,5 & 17,2 & 100 \\
\hline Mais de $13 \mathrm{SM}$ & 20,7 & 60,6 & 18,7 & 100 \\
\hline \multicolumn{5}{|c|}{ Qui-quadrado 123.419 significativo ao nível de $p<.000$} \\
\hline \multicolumn{5}{|c|}{ Escolaridade } \\
\hline Sem instrução & 66,9 & 24,3 & 8,9 & 100 \\
\hline Até $4^{\mathrm{a}}$. série & 52,3 & 36,2 & 11,6 & 100 \\
\hline De $5^{\mathrm{a}}$ a $8^{\mathrm{a}}$. série & 35,6 & 53,2 & 11,2 & 100 \\
\hline $2^{\circ}$. grau & 28,3 & 61,8 & 9,9 & 100 \\
\hline Superior ou mais & 17,7 & 65,0 & 17,4 & 100 \\
\hline \multicolumn{5}{|c|}{ Qui-quadrado 221.416 significativo ao nível de $p<.000$} \\
\hline \multicolumn{5}{|c|}{ Idade } \\
\hline De 16 a 24 anos & 31,0 & 59,9 & 9,1 & 100 \\
\hline De 25 a 34 anos & 29,7 & 58,8 & 11,6 & 100 \\
\hline De 35 a 44 anos & 34,5 & 52,2 & 13,3 & 100 \\
\hline De 45 a 59 anos & 42,0 & 46,8 & 11,2 & 100 \\
\hline De 60 anos ou mais & 57,2 & 30,6 & 12,2 & 100 \\
\hline
\end{tabular}

Fonte: ESEB 2002 
NISHIMURA, Kátia M. Conservadorismo social:...

\section{Sobre a hierarquia social}

Para tratar do tema da hierarquia social junto à sociedade brasileira foram tomadas três situações em que se poderiam perceber algumas de suas noções entre os entrevistados. Em uma das questões foi perguntada qual a atitude que os empregados de um prédio deveriam ter se lhes fosse dito pelos moradores para utilizarem também o elevador social. Outra pergunta apresentava uma situação em que o patrão permitia ao empregado tomar banho na piscina do edifício em que trabalhava e indagava o entrevistado sobre qual atitude o empregado deveria tomar. A terceira situação apresentada perguntava a atitude que um empregado deveria ter se o patrão lhe dissesse que ele poderia ser tratado por "você" e não mais por "senhor". Nestas três situações, a maioria dos entrevistados apontou atitudes que se desdobram no sentido de reforçar as hierarquias existentes, confirmando de certo modo a sua presença também na dinâmica das relações sociais. Da Matta identificou em nossa sociedade um sistema social extremamente preocupado com a idéia do "cada qual no seu lugar", ou seja, com a hierarquia e com a autoridade, e uma característica básica deste sistema é denunciada pelo já conhecido "sabe com quem está falando?" que não deve ser considerado uma mania ou modismo de uma camada social específica, mas encarado como uma forma socialmente estabelecida (DA MATTA, 1997). Os resultados dos dados sobre as situações apresentadas acima parecem confirmar este quadro descrito pelo autor.

Os dados da Tabela 17 mostram que, independentemente da escolha política na eleição presidencial de 2002, a maioria dos entrevistados optou pela atitude do empregado recusar o convite do patrão para tomar banho na piscina do edifício, o que vale tanto para os eleitores de Lula como os de Ciro Gomes, José Serra, Garotinho e José Maria. Nas outras duas situações: a atitude frente à permissão de uso do elevador social por empregados e a atitude frente à flexibilização do tratamento pessoal, com exceção da maioria dos eleitores do candidato do PSTU, os posicionamentos da maior parte dos eleitores dos demais candidatos continuaram no sentido de manter "as coisas como estão", ou seja, o patrão deve continuar sendo tratado por senhor e os empregados devem continuar usando o elevador de serviço. 


\section{Tabela 17}

Hierarquia Social e Voto em $2002(\%)$

\begin{tabular}{|c|c|c|c|c|c|}
\hline & Lula & $\begin{array}{c}\text { Ciro } \\
\text { Gomes } \\
\end{array}$ & $\begin{array}{l}\text { José } \\
\text { Serra }\end{array}$ & Garotinho & $\begin{array}{l}\text { José } \\
\text { Maria }\end{array}$ \\
\hline $\begin{array}{l}\text { Atitude que um empregado deveria ter se o } \\
\text { patrão lhe diz que pode ser tratado de você... } \\
\text { Continuar chamado o patrão por senhor. }\left(^{*}\right)\end{array}$ & 61,1 & 61,3 & 51,4 & 69,1 & 33,3 \\
\hline $\begin{array}{l}\text { Atitude que o empregado deveria ter se o patrão } \\
\text { diz que ele pode tomar banho na piscina do } \\
\text { edifício... Agradecer e não tomar banho na } \\
\text { piscina. }{ }^{* *} \text { ) }\end{array}$ & 64,7 & 53,1 & 63,1 & 64,2 & 66,7 \\
\hline $\begin{array}{l}\text { Atitude que os empregados de um prédio } \\
\text { deveriam ter se os moradores dizem que eles } \\
\text { podem usar o elevador social... Continuar } \\
\text { usando o elevador de serviço. }{ }^{* * *} \text {. }\end{array}$ & 57,4 & 50,8 & 58,6 & 58,8 & 16,7 \\
\hline
\end{tabular}

$\left(^{*}\right)$ Qui-quadrado 25.777 significativo ao nível de $p<.000$

$\left.{ }^{* *}\right)$ Qui-quadrado 9.819 significativo ao nível de $p<.05$

$\left.{ }^{(* \star *}\right)$ Qui-quadrado 7.943 significativo ao nível de $p<.10$

Fonte: ESEB 2002

Novamente, é a faixa de maior idade que apresenta o maior número de opiniões favoráveis à manutenção das hierarquias existentes. Diferentemente de outras questões em que os jovens tendem a apresentar posturas menos conservadoras, nessas questões que abordam o tema da hierarquia social, os mais jovens não têm se destacado devido aos seus posicionamentos igualitários. Este é um dado importante para se pensar como essas noções de hierarquia social, como elementos de classificação em um sistema social mais amplo e como características da cultura brasileira, estão de tal modo enraizadas no cotidiano das relações sociais que são percebidas por todos como algo a ser mantido. (Tabela 18) 
NISHIMURA, Kátia M. Conservadorismo social:...

\section{Tabela 18}

Atitudes em relação à Hierarquia Social por Faixas de Idade (\%)

\begin{tabular}{|c|c|c|c|c|c|}
\hline Atitudes & $\begin{array}{l}\text { De } 16 \text { a } \\
24 \text { anos }\end{array}$ & $\begin{array}{l}\text { De } 25 \text { a } \\
34 \text { anos }\end{array}$ & $\begin{array}{l}\text { De } 35 \text { a } \\
44 \text { anos }\end{array}$ & $\begin{array}{l}\text { De } 45 \text { a } \\
59 \text { anos }\end{array}$ & $\begin{array}{c}\text { De } 60 \\
\text { anos ou } \\
\text { mais }\end{array}$ \\
\hline $\begin{array}{l}\text { Atitude que um empregado deveria ter se o } \\
\text { patrão lhe diz que pode ser tratado de você... } \\
\text { Continuar chamado o patrão por senhor. }\left(^{*}\right)\end{array}$ & 53,5 & 55,7 & 60,3 & 65,4 & 69,8 \\
\hline $\begin{array}{l}\text { Atitude que o empregado deveria ter se o patrão } \\
\text { diz que ele pode tomar banho na piscina do } \\
\text { edifício... Agradecer e não tomar banho na } \\
\text { piscina. }\left(^{* *}\right)\end{array}$ & 55,9 & 63,5 & 63,9 & 65,2 & 68,2 \\
\hline $\begin{array}{l}\text { Atitude que os empregados de um prédio } \\
\text { deveriam ter se os moradores dizem que eles } \\
\text { podem usar o elevador social... Continuar } \\
\text { usando o elevador de serviço. }\left(^{* * *}\right)\end{array}$ & 51,5 & 54,5 & 55,1 & 59,8 & 66,8 \\
\hline $\begin{array}{l}\left.{ }^{*}\right) \text { Qui-quadrado } 32.348 \text { significativo ao nível de } \\
\left({ }^{* *}\right) \text { Qui-quadrado } 15.054 \text { significativo ao nível de } \\
\left({ }^{* * *}\right) \text { Qui-quadrado } 22.267 \text { significativo ao nível de }\end{array}$ & $\begin{array}{l}p<.000 \\
p<.005 \\
e<.000\end{array}$ & & & & \\
\hline
\end{tabular}

Fonte: ESEB 2002

Outro elemento importante a destacar é o fato destes posicionamentos se localizarem entre alguns grupos situados em determinados estratos da estrutura social. Novamente, as variáveis renda e escolaridade são elementos diferenciadores das opiniões. É entre os estratos de renda média baixa e de pouca ou média escolaridade que se concentram as posturas mais conservadoras.

A variável raça é importante para essa análise, considerando que é nesse sistema social, em que as hierarquias se estabelecem, que os mais pobres, assim como os negros e os mestiços são os mais discriminados e vítimas de preconceitos de vários tipos (CALDEIRA, 1991). Na pesquisa do ESEB foram empregados os termos utilizados pelo IBGE para a classificação da cor ou raça das pessoas: preto, pardo, branco, amarelo e índio ${ }^{13}$.

É justamente entre aqueles que mais sofrem as discriminações e preconceitos no cotidiano que as noções de hierarquia e de "lugares sociais" são mais percebidas. Como destacou Da Matta, temos um sistema social com aspectos conhecidos "mas não reconhecido pelos seus membros" (DA MATTA, 1997, p.185). É

\footnotetext{
${ }^{13}$ A pergunta, do tipo estimulada, apresentava-se da seguinte forma no questionário: "O IBGE - instituto que faz os censos no Brasil - usa os termos preto, pardo, branco, amarelo e índio para classificar a cor ou raça das pessoas. qual desses termos descreve melhor a sua cor ou raça:".
} 
entre os entrevistados que se auto-declararam negros, pardos (mestiços) e índios que encontramos, comparativamente, o maior número de respostas favoráveis a atitudes no sentido de se manter a situação estabelecida. Já os entrevistados que se auto-declararam amarelos, termo no qual são incluídos descendentes de japoneses, chineses e orientais, apontaram, em maior número, atitudes opostas às apresentadas por brancos e negros nas três situações apresentadas. Pode-se sugerir que este grupo sócio-cultural não apresenta as mesmas noções de hierarquia devido à sua herança cultural, e porque as formas e tipos de discriminação social e cultural que sofrem não se configuram da mesma forma que aquela conhecida por negros e mestiços em nossa sociedade. (Tabelas 19 a 22)

\section{Tabela 19}

\section{Hierarquia Social segundo Renda e Escolaridade I (\%)}

Atitude que os empregados de um prédio deveriam tomar se os moradores dissessem que eles poderiam usar o elevador social

Deveriam continuar usando o elevador de serviço

\begin{tabular}{rr|rr}
\multicolumn{2}{c}{ Escolaridade } & Renda \\
\hline \hline Sem instrução & 76,6 & Sem Renda & 73,7 \\
Até 4 ${ }^{\text {a }}$. série & 68,9 & Até 1 SM & 70,8 \\
De $\mathbf{5}^{\text {a a }} \mathbf{8}^{\text {a }}$. série & 63,5 & De mais de 1 a 4 SM & 64,0 \\
$\mathbf{2}^{\circ}$. grau & 48,8 & De mais de 4 a 7 SM & 52,0 \\
Superior ou mais & 30,2 & De mais de 7 a 10 SM & 40,9 \\
& & De mais de 10 a 13 SM & 54,1 \\
& & Mais de 13 SM & 35,1 \\
\hline \hline Qui-quadrado 186.686 significativo ao nível de & Qui-quadrado 115.656 significativo ao nível de \\
p<.000 & p<.000 & & \\
\hline \hline
\end{tabular}

Fonte: ESEB 2002 


\section{Tabela 20}

Hierarquia Social por Renda e Escolaridade II (\%)

Atitude que o empregado deveria ter se o patrão lhe diz que ele pode ser tratado de você Deveriam continuar chamando o patrão por senhor

\begin{tabular}{|c|c|c|c|}
\hline \multicolumn{2}{|l|}{ Escolaridade } & \multicolumn{2}{|l|}{ Renda } \\
\hline Sem instrução & 78,4 & Sem Renda & 80,5 \\
\hline Até $4^{\mathrm{a}}$. série & 71,0 & Até $1 \mathrm{SM}$ & 72,5 \\
\hline De $5^{\mathrm{a}}$ a $8^{\mathrm{a}}$. série & 64,5 & De mais de 1 a $4 \mathrm{SM}$ & 66,0 \\
\hline $2^{\circ}$.grau & 52,9 & De mais de 4 a $7 \mathrm{SM}$ & 52,7 \\
\hline \multirow[t]{3}{*}{ Superior ou mais } & 39,2 & De mais de 7 a $10 \mathrm{SM}$ & 49,2 \\
\hline & & De mais de 10 a $13 \mathrm{SM}$ & 42,6 \\
\hline & & Mais de $13 \mathrm{SM}$ & 36,6 \\
\hline \multicolumn{2}{|c|}{$\begin{array}{l}\text { Qui-quadrado } 138.092 \text { significativo ao nível de } \\
p<.000\end{array}$} & \multicolumn{2}{|c|}{$\begin{array}{l}\text { Qui-quadrado } 114.456 \text { significativo ao nível de } \\
p<.000\end{array}$} \\
\hline
\end{tabular}

Fonte: ESEB 2002

Tabela 21

Hierarquia Social por Renda e Escolaridade III (\%)

Atitude que o empregado deveria ter se o patrão lhe diz que ele pode tomar banho na piscina do edifício...

Agradecer e não tomar banho na piscina.

\begin{tabular}{|c|c|c|c|}
\hline \multicolumn{2}{|l|}{ Escolaridade } & \multicolumn{2}{|l|}{ Renda } \\
\hline Sem instrução & 73,1 & Sem Renda & 84,6 \\
\hline Até $4^{\mathrm{a}}$. série & 72,6 & Até $1 \mathrm{SM}$ & 69,8 \\
\hline De $5^{\mathrm{a}}$ a $8^{\mathrm{a}}$. série & 70,2 & De mais de 1 a $4 \mathrm{SM}$ & 70,5 \\
\hline $2^{\circ}$. grau & 56,9 & De mais de 4 a $7 \mathrm{SM}$ & 59,9 \\
\hline \multirow[t]{3}{*}{ Superior ou mais } & 41,4 & De mais de 7 a $10 \mathrm{SM}$ & 44,7 \\
\hline & & De mais de 10 a $13 \mathrm{SM}$ & 56,7 \\
\hline & & Mais de $13 \mathrm{SM}$ & 45,1 \\
\hline \multicolumn{2}{|c|}{$\begin{array}{l}\text { Qui-quadrado } 122.235 \text { significativo ao nível de } \\
p<.000\end{array}$} & \multicolumn{2}{|l|}{$\begin{array}{l}\text { Qui-quadrado } 106.562 \text { significativo ao nível de } \\
p<.000\end{array}$} \\
\hline
\end{tabular}

Fonte: ESEB 2002 
OPINIÃO PÚBLICA, Campinas, Vol. X, no 2, Outubro, 2004, p. 339-367

Tabela 22

Atitudes em relação à Hierarquia Social segundo a Cor ou Raça (\%)

\begin{tabular}{|c|c|c|c|c|c|}
\hline Atitudes & Branco & Pardo & Preto & Amarelo & Índio \\
\hline $\begin{array}{l}\text { Atitude que um empregado deveria ter se o } \\
\text { patrão lhe diz que pode ser tratado de você... } \\
\text { Continuar chamado o patrão por senhor. }\left(^{*}\right)\end{array}$ & 56,9 & 62,5 & 70,3 & 36,4 & 73,1 \\
\hline $\begin{array}{l}\text { Atitude que o empregado deveria ter se o patrão } \\
\text { diz que ele pode tomar banho na piscina do } \\
\text { edifício... Agradecer e não tomar banho na } \\
\text { piscina. }\left({ }^{* *}\right)\end{array}$ & 58,7 & 67,8 & 68,2 & 42,4 & 68,0 \\
\hline $\begin{array}{l}\text { Atitude que os empregados de um prédio } \\
\text { deveriam ter se os moradores dizem que eles } \\
\text { podem usar o elevador social... Continuar } \\
\text { usando o elevador de serviço. }\left(^{* * *}\right)\end{array}$ & 52,1 & 62,9 & 60,9 & 27,3 & 56,0 \\
\hline
\end{tabular}

$\left({ }^{*}\right)$ Qui-quadrado 29.414 significativo ao nível de $p<.000$

$\left.{ }^{* *}\right)$ Qui-quadrado 27.793 significativo ao nível de $p<.000$

${ }^{(* *)}$ Qui-quadrado 37.700 significativo ao nível de $p<.000$

Fonte: ESEB 2002

$* * *$

Em linhas gerais, os dados analisados neste artigo apontaram algumas tendências para compreender o comportamento social da sociedade brasileira; pode-se dizer que os temas aqui tratados configuram indicadores de um conservadorismo social. As tendências observadas remetem ao autoritarismo social destacado por Dagnino (1994), que caracteriza uma sociedade pautada pela organização hierárquica e desigual do conjunto das relações sociais. 0 autoritarismo social se baseia em critérios de raça, classe e gênero, produzindo formas de sociabilidade e uma cultura autoritária de exclusão que podem ser verificadas no conjunto das práticas sociais, alimentando e reproduzindo a desigualdade nos diferentes níveis das relações sociais. As questões aqui observadas, sobre o papel da mulher, o aborto, o homossexualismo e a hierarquia social, estão relacionadas diretamente às desigualdades de tratamento que se colocam como obstáculos à possibilidade de uma efetiva democratização das relações sociais na sociedade brasileira. 
Sales (1994) observou que as raízes da desigualdade social na cultura política brasileira remetem às relações de mando e subserviência características de uma ordem social hierarquizada que sobrevive até os dias de hoje. Essa ordem social desigual e hierárquica é mantida e mascarada pela cordialidade, que permeia as relações sociais e dá a aparência de encurtamento das distâncias através da informalidade no convívio, de modo que as desigualdades sociais são reproduzidas e amenizadas no cotidiano. Os posicionamentos e atitudes apresentados pelos entrevistados no que diz respeito às questões de hierarquia social parecem apontar neste sentido. O que os resultados mostram é que as noções de hierarquia e a idéia de "lugares sociais" estão de tal forma enraizados na nossa cultura que, independentemente do status socioeconômico, do grau de escolaridade e da faixa etária, verifica-se um posicionamento favorável à manutenção da ordem social vigente. O dado mais perverso deste ordenamento social é que mesmo as maiores vítimas dos mais freqüentes tipos de preconceitos e discriminações, pobres, negros e mestiços, são também favoráveis à existência do "elevador de serviço" e de outros "lugares sociais" estabelecidos pelo autoritarismo social.

Nessa organização hierárquica e desigual, a mulher ocupa uma posição inferior em relação ao homem. Os papéis de cada um são diferenciados e os femininos são menos valorizados. Como destacou Machado (1996), “a mulher está associada à família e à casa e o homem ao mercado e à política, esferas de atuação extremamente valorizadas na sociedade, que acabam colocando os maridos em posição de superioridade diante das esposas" (MACHADO, 1996, p. 80). As questões referentes ao papel da mulher e aos seus direitos abordadas na pesquisa tiveram uma repercussão menos conservadora entre os entrevistados: a maioria dos homens e das mulheres de várias faixas etárias, de diferentes níveis de escolaridade e status socioeconômicos posicionou-se de acordo com a divisão das atividades do lar e da defesa dos direitos da mulher. Estas opiniões também foram encontradas entre a maioria do eleitorado dos vários candidatos à presidência em 2002, embora seja necessário lembrar a ocorrência, entre os eleitores de Garotinho, do maior número de respostas conservadoras em relação a esse tema. Este mesmo eleitorado destacou-se por apresentar os posicionamentos mais conservadores nas questões do aborto e do homossexualismo, temas relacionados à esfera moral. Uma hipótese desenvolvida a partir desses resultados considera o peso da dimensão religiosa dos valores morais nessas opiniões, dado que parcela significativa dos evangélicos entrevistados votou no candidato do PSB.

Um elemento importante a destacar trazido por esses dados, e que reforça uma tendência já observada em outros estudos, diz respeito à caracterização socioeconômica e demográfica dos conservadores. A tendência de opiniões e atitudes conservadoras foi predominantemente observada entre os menos escolarizados, com renda média ou baixa e com mais idade. 
Finalmente, os resultados aqui observados indicam uma presença expressiva de opiniões e atitudes conservadoras na dinâmica do cotidiano da sociedade brasileira, dificultando significativamente o processo de democratização das relações sociais. As tendências apontam para a necessidade da continuidade de uma investigação neste sentido.

\section{Bibliografia}

ANTENORE, Armando. Pastor prega voto evangélico contra 'raça gay'. Caderno Especial Folha de S. Paulo, p. 09, 29 de setembro de 2002.

BABBIE, Earl. Métodos de Pesquisas de Survey. Belo Horizonte, Ed. UFMG, 1999.

BERABA, Marcelo. Influência da Universal preocupa Igreja Católica. Folha de S. Paulo, Caderno Especial 2, Eleições 2002, 28 de outubro de 2002.

CALDEIRA, Teresa Pires do Rio. Direitos humanos ou "privilégios de bandidos"? Novos Estudos Cebrap. São Paulo, (30), p. 162-174, julho, 1991.

DAGNINO, Evelina. Os movimentos sociais e a emergência de uma nova noção de cidadania. In: DAGNINO, Evelina (org.). Os anos 90: Política e Sociedade no Brasil. São Paulo, Brasiliense, 1994.

DA MATTA, Roberto. Sabe com quem está falando?. Carnavais, malandros e heróis: para uma sociologia do dilema brasileiro. $6^{\mathrm{a}}$. edição. Rio de Janeiro, Zahar, 1997.

DIMENSTEIN, Gilberto. Jardim dos gays. Folha de S. Paulo, p. C2, 10 de julho de 2002.

Folha de S. Paulo. 130 homossexuais foram mortos em 97, 27 de janeiro de 1998.

Folha de S. Paulo. Igreja: João Paulo II diz que homossexualismo é anomalia. Papa critica manifestação de homossexuais na capital italiana, 10 de julho de 2000.

Folha de S. Paulo. Geografia do preconceito, p. A4, 20 de maio de 2002. 
Folha de S. Paulo. Não sou frango", diz Garotinho, que é contrário à união civil de homossexuais, p. C4, 18 de maio de 2002.

Folha de S. Paulo. Garotinho diz que, eleito, veta união de homossexuais. p. A6, 07 de junho de 2002.

FRANCISCO, Luiz. Discriminação: Brasil lidera crime contra homossexual. Folha de S. Paulo, 04 de abril de 2000.

GAARDNER, Jostein. O Livro das Religiões. São Paulo: Companhia das Letras.

KAHN, Túlio. O ataque careca. Folha de S. Paulo, p. 1-3, 14 de fevereiro de 2000.

LEONEL, Vange. Vice Mulher. Revista da Folha, p. 41, 16 de junho de 2002.

. O fruto da ignorância. Revista da Folha, p. 56, 20 de outubro de 2002.

MACHADO, Maria das Dores Campos. Carismáticos e Pentecostais: Adesão Religiosa na Esfera Familiar. Campinas: Autores Associados; São Paulo: ANPOCS, 1996.

MARIANO, Ricardo. Neopentecostais: Sociologia do Novo Pentecostalismo no Brasil. São Paulo: Ed. Loyola, 1999.

MOTT, Luiz. Os presidenciáveis e os homossexuais. Folha de S. Paulo, Opinião, p. A3, 26 de setembro de 2002.

PIERUCCI, Antônio Flávio. Representantes de Deus em Brasília: a Bancada Evangélica na Constituinte. Ciências Sociais Hoje, 1989.

PIERUCCI, Antônio Flavio. Apêndice. Em HELLERN, Victor; NOTAKER, Henry; 2000.

SALES, Teresa. Raízes da desigualdade social na cultura política brasileira. Revista Brasileira de Ciências Sociais, ano 9 (25), p. 26-37, junho, 1994. 